\title{
INCIDENCIA DE LA INAPLICACIÓN DEL PRINCIPIO DE PLAZO RAZONABLE EN LA INEFICIENCIA DE LA ETAPA DE INVESTIGACIÓN PREPARATORIA EN LOS CASOS DE PRISIÓN PREVENTIVA EN EL DISTRITO FISCAL DE TACNA. 2013-2014
}

\author{
INCIDENCE OF NON-APPLICATION OF THE REASONABLE TIME PRINCIPLE IN THE \\ INEFFICIENCY OF THE PREPARATORY INVESTIGATION STAGE IN CASES OF PRE-TRIAL \\ DETENTION IN THE FISCAL DISTRICT OF TACNA. 2013-2014
}

\section{Diana Beatriz Arcaya Pancca ${ }^{4}$}

\section{RESUMEN}

Objetivo: El objetivo de la presente investigación fue determinar la incidencia de la inaplicación del principio de Plazo Razonable en la ineficiencia de la Etapa de Investigación Preparatoria en los casos de prisión preventiva en el Distrito Fiscal de Tacna, periodo 20132014

Material y metodo: La hipótesis de estudio fue: En el Distrito Fiscal de Tacna la inaplicación del principio de Plazo Razonable incide significativamente en la ineficiencia de la Etapa de Investigación Preparatoria en los casos de prisión preventiva, periodo 2013-2014. El tipo de investigación es Aplicada. El estudio corresponde al diseño no experimental (ex post facto). Asimismo, corresponde a un diseño Descriptivo - Explicativo. Desde el punto de vista geográfico el presente trabajo de investigación es departamental, dado que el estudio comprende los casos de prisión preventiva en el Distrito Fiscal de Tacna. Para tal propósito se consideró la información obtenida a través de la aplicación del cuestionario, cédulas de entrevistas y la ficha de análisis; como instrumentos de medición de las variables a estudiar.

Resultados: Una vez finalizada la fase de análisis e interpretación de los resultados se precisó que: a) En la etapa de Investigación Preparatoria en los casos de prisión preventiva, se incumple con aplicar el Principio de Plazo Razonable atendiendo a las necesidades concretas de la investigación, en el Distrito Fiscal de Tacna, periodo 2013-2014; b) La etapa de Investigación Preparatoria en los casos de prisión preventiva, en el Distrito Fiscal de Tacna, periodo 2013-2014, es ineficiente, comprobándose de esta manera la hipótesis de investigación.

Conclusión: En la etapa de Investigación Preparatoria en los casos de prisión preventiva, se incumple con aplicar el principio de Plazo
Razonable atendiendo las necesidades concretas de la investigación, en el Distrito Fiscal de Tacna durante los años 2013-2014.

\begin{abstract}
Palabras claves: Principio del Plazo Razonable, eficiencia de la Etapa de Investigación Preparatoria, máximo plazo legal, morosidad, complejidad de la investigación.
\end{abstract}

\section{ABSTRAC}

Objective: The objective of the present investigation was to determine the incidence of non-application of the principle of Reasonable Term in the inefficiency of the Preparatory Investigation Stage in cases of pretrial detention in the Fiscal District of Tacna, period 20132014.

Material and method: The hypothesis of study was: In the Fiscal District of Tacna the nonapplication of the principle of Reasonable Term significantly influences the inefficiency of the Preparatory Investigation Stage in the cases of preventive detention, period 2013-2014. The type of research is Applied. The study corresponds to the non-experimental design (ex post facto). Likewise, it corresponds to a Descriptive - Explicative design. From the geographic point of view this research work is departmental, since the study includes the cases of preventive detention in the Fiscal District of Tacna. For this purpose, the information obtained through the application of the questionnaire, interview cards and the analysis sheet were considered; As instruments of measurement of the variables to be studied.

Results: Once the phase of analysis and interpretation of the results was completed, it was specified that: a) At the stage of Preparatory Investigation in cases of pre-trial detention, it is not possible to apply the Reasonable Term Principle, taking into account the specific needs of the investigation, In the Tax District of Tacna, period 2013-2014; B) The

${ }^{4}$ Magister en derecho con mención en Ciencias Penales 
stage of Preparatory Investigation in cases of preventive detention, in the Tax District of Tacna, period 2013-2014, is inefficient, thus proving the research hypothesis.

Conclusion: In the stage of Preparatory Investigation in cases of pre-trial detention, it is imperative to apply the principle of Reasonable
Term, taking into account the specific needs of the investigation, in the Fiscal District of Tacna during the years 2013-2014.

Key words: Principle of the Reasonable Term, efficiency of the Preparatory Research Stage, maximum legal term, delays, complexity of the investigation.

\section{INTRODUCCIÓN}

Uno de los graves problemas que ha debido enfrentar desde siempre el proceso penal, es la duración del mismo, atendido principalmente a que durante el enjuiciamiento los derechos del imputado no solo son limitados, sino que pueden llegar a ser anulados completamente. Es por ello que se debe propender a que la duración de este proceso sea lo más breve posible, más aún si se tiene presente que no solo las libertades de quien es sometido a enjuiciamiento se ven conculcadas con un proceso cuya duración exceda lo razonable, sino que además con ello se afecta a su dignidad y honra, y las de su entorno familiar.

A fin de evitar las limitaciones y contravenciones a los derechos fundamentales que se producen en procesos penales que duran eternamente, se ha recogido por los ordenamientos jurídicos, desde los orígenes de Roma, el derecho a ser juzgado lo más rápido posible, derecho que en la actualidad ha tomado el nombre de "derecho a ser juzgado en un plazo razonable o sin dilaciones indebidas". Este derecho en la antigüedad lo encontramos plasmado principalmente en las normas sustanciales y procedimentales. Es así como Justiniano establecía que los procesos no debían durar más allá de la vida de los enjuiciados, y posteriormente Constantino indicaba plazos precisos y bastante exiguos para la duración del proceso penal, señalando expresamente desde y hasta cuándo se contaban los plazos. Desde aquella época a la actual este derecho, sin bien siempre ha estado presente, se ha manifestado de diferentes formas, ya que en algunos ordenamientos se ha consagrado expresamente, pero en otros se ha subsumido o se ha incorporado a otros derechos más amplios por vías de interpretación, principalmente aquella efectuada por los tribunales internacionales.

Esta es la tendencia actual en torno al derecho a ser juzgado sin dilaciones indebidas, ya que su contenido y alcance ha surgido principalmente de la jurisprudencia de los tribunales internacionales, quienes a partir de la interpretación de las normas y derechos incluidos en los tratados y convenciones supranacionales, han tratado de explicar cuál es el alcance de este derecho, cuál es la forma de determinar su transgresión y cuáles son las sanciones que conlleva la contravención del mismo.

Nuestro país, no ha estado ajeno al quehacer internacional en esta materia y desde el Código Procesal Penal aprobado por Decreto Legislativo $N^{\circ}$ 957, vigente en parte del país, en el Art. I del Título Preliminar indica que "La justicia penal es gratuita, salvo el pago de las costas procesales establecidas conforme a esta Código. Se imparte con imparcialidad por los órganos jurisdiccionales competentes y en un plazo razonable", como también mediante mecanismos que garantizan el respeto de esta garantía, principalmente a través de la imposición para los intervinientes en el proceso penal, especialmente para el órgano encargado de ejercer la labor punitiva del Estado, que es Ministerio Público, plazos precisos y breves para ejercer la labor punitiva del estado.

La duración del plazo de investigación en la etapa de investigación preparatoria es y ha sido un problema, pese a la vigencia del Nuevo Código Procesal Penal en el Distrito Fiscal de Tacna, aún existe índices considerables de plazos excesivos por la cultura burocrática, de gestión o de mero trámite de los Representantes del Ministerio Público. 
El plazo razonable constituye una garantía fundamental integrante del Debido Proceso cuya duración debe sujetarse a criterios de razonabilidad y proporcionalidad, para cada caso en concreto; por tanto, debe tenerse siempre presente que las diligencias de la investigación preparatoria son diligencias de investigación que el Representante del Ministerio Público considere pertinentes y útiles, dentro de los límites de la Ley.

La racionalidad legal normativa, es el extremo máximo evaluado por el legislador, en abstracto; empero, esa es una primera aproximación, dado que corresponderá a los órganos jurisdiccionales establecer la razonabilidad en concreto del plazo en función de las necesidades reales de la investigación. En la actualidad se observa que el Representante del Ministerio Público no aplica el principio de Plazo Razonable en la etapa de investigación preparatoria en los casos seguidos contra presos preventivos, por lo que, trae como consecuencia que se utilice generalmente el máximo del plazo legal sin atender a las necesidades concretas de la investigación. Es probable, que en las investigaciones de presos preventivos el Fiscal ha reunido los suficientes elementos de convicción que han determinado su situación jurídica procesal, por lo que, los actos de investigación una vez formalizada la investigación preparatoria deberían ser mínimos y en un plazo razonable, lo cual no justifica el uso del máximo del plazo legal.

Es el tiempo consumido en la tramitación de diversos procesos, que fue señalado por los solicitantes de tutela jurisdiccional constitucional como excesivo y lesivo a diversos derechos fundamentales, incluido el plazo razonable. La reacción contra la morosidad de procesos penales, constitucionales y administrativos, que conjuntamente con las quejas por la duración de la prisión preventiva, constituyen un vasto y rico escenario que el Tribunal Constitucional ha debido ordenar. Toda actividad humana, incluidas las realizadas como manifestación del poder y funciones del Estado, sólo puede existir como un evento finito en el tiempo, con un inicio y un término. Sin embargo, debe decirse que el simple transcurso del tiempo, por más dilatado que se muestre a la subjetividad de un observador, por sí sólo, no es elemento suficiente que permita calificar de legítima o ilegítima la duración de un proceso. La actividad del Estado es una función de los diversos fines que la organización social ha estipulado en la Constitución para la satisfacción de diversas necesidades individuales y sistémicas. No obstante, únicamente la realización oportuna de la intervención estatal será legítima, valiosa y útil para la sociedad, porque el supuesto contrario, que incluye las omisiones o realizaciones prolongadas, constituye una negación del Derecho y del Estado como instrumentos de convivencia. En este orden de ideas, el Tribunal Constitucional ha dicho que la persecución pública del delito implica la restricción de diversos derechos (sobre todo la libertad personal), circunstancia que constituye una exigencia adicional para el cese de la afectación, a través de la pronta determinación de la situación jurídica de los procesados.

El proceso penal es resultado de diversas fuerzas que interactúan ordenada y dinámicamente, debiendo orientar sus propios objetivos en función de los fines del proceso. El resultado de un proceso que se desenvuelve ajustado a los parámetros constitucionales es el equilibrio que se manifiesta como una impronta singular de cada caso concreto, igual que su duración. En este sentido el Tribunal Constitucional ha sostenido que: "(...) es necesario establecer de forma categórica que el plazo razonable no es un derecho que pueda ser "medido" de manera objetiva, toda vez que resulta imposible asignar a los procesos penales una uniformidad objetiva $e$ incontrovertida; lo que si se puede hacer si merituamos dicho plazo a partir del caso concreto (...)" (Exp. $\mathrm{N}^{\circ}$ 04931-2007-HC, fundamento 4).

Nuestra Carta Fundamental no reconoce en forma explícita este derecho fundamental sin que por ello deje de ser exigible ante los tribunales de nuestro país, porque es una manifestación implícita del derecho a la libertad personal y constituye parte del núcleo mínimo de derechos del sistema interamericano.

La gran importancia del derecho de defensa, ha requerido que diferentes instrumentos internacionales, tuitivos de los derechos fundamentales, reconozcan la necesidad de un plazo razonable para su ejercicio. 
El tiempo razonable para preparar la defensa, se encuentra apuntalado en el derecho de presunción de inocencia y concurre con otras garantías como componentes integrantes del derecho a un debido proceso, como ha dicho el Tribunal Constitucional:

"Algunas de las garantías judiciales mínimas reconocidas a la defensa son: (i) la presunción de inocencia; (ii) la comunicación previa y detallada de la acusación formulada; (iii) el plazo razonable para la preparación de la defensa; (iv) el derecho de defensa técnica; (v) el derecho a tener un defensor; (vi) el derecho a interrogar testigos; (vii) el derecho a no auto inculparse; y (viii) el derecho a presentar un recurso de apelación." (Exp. N 00926-2007-PA, fundamento 32).

El derecho fundamental en cuestión tiene una finalidad específica, precisa y clara: evitar que las personas sometidas a proceso penal sean efectivamente perseguidas más allá de un plazo cierto. Esta circunstancia y su reconocimiento como derecho subjetivo del imputado son imperativos insoslayables del Estado de derecho como sistema de limitaciones jurídicas del poder penal público. Este poder es limitado, legal y estrictamente, en cuanto a su ámbito de aplicación (marco de lo prohibido o mandado penalmente), en cuanto al tipo y medida, legales y estrictas, de su reacción (clase de pena y su duración o marco de duración) y también en cuanto a las formas, legales y estrictas, de su realización (debido proceso legal). En estos tres ámbitos la libertad de las personas, ya se dijo, se ve sensiblemente limitada por la actividad del Estado. Ello sólo puede ser tolerado, desde el punto de vista del Estado de derecho, en tanto y en cuanto, además de responder a otros principios básicos (necesidad, subsidiariedad, proporcionalidad, etc.), estas restricciones estén dispuestas por la ley y tengan límites precisos. El proceso penal mismo representa un ejercicio permanente de coerción sobre la persona del imputado que; por definición, debe soportar el ser sometido forzosamente a juicio. Esta naturaleza del proceso, eminentemente lesiva para la libertad individual, es reconocida y legalmente encauzada por el orden jurídico.

Hasta hoy, por lo tanto, el único plazo que ha logrado reconocimiento legislativo en los Estados civilizados es el de la prisión preventiva, aunque también en esto alguna jurisprudencia ha intentado derogarlo con el argumento disparatado, nacido para la ocasión pero luego traspolado también a la discusión sobre la excesiva duración del proceso, de que un plazo no se puede contar en días, semanas, meses o años. Ya se ha demostrado una característica central del Estado de derecho exige que las limitaciones del poder penal del Estado estén rigurosamente determinadas por la ley y ex ante factum, Esto rige tanto para la medida de coerción procesal que se encarna en la prisión preventiva como para el proceso, que es en sí mismo de un modo indudable una coerción procesal permanente o, mejor dicho, "la coerción procesal" misma. Es por ello también que prisión preventiva y proceso se asimilan sabiamente en cierto plano o punto de vista. La prisión preventiva está ya limitada, por reglas expresas de garantía, en sus fundamentos de procedencia; en su ámbito de actuación. Lo mismo vale para el proceso, que no puede ser cualquiera, sino uno acorde al respeto por las garantías judiciales del individuo. La relación se estrecha, por una parte, debido a que si el régimen del encarcelamiento preventivo no se conforma al orden constitucional, entonces, lógicamente, tampoco el proceso al que sirve puede ser constitucionalmente adecuado.

\section{MATERIALES Y MÉTODO}

La forma de investigación es una Investigación Aplicada, porque está orientada en la aplicación de los conocimientos a la solución de un problema, pues confronta la teoría con la realidad. También es un tipo de Investigación Socio Jurídica porque se estudian los hechos y relaciones de orden social reguladas por normas jurídicas y porque se pretende determinar la incidencia de la inaplicación del principio de Plazo Razonable en la ineficiencia de la etapa de Investigación Preparatoria en los casos de prisión preventiva en el Distrito Fiscal de Tacna durante los años 2013-2014.

El estudio correspondió a una investigación jurídico-social, siendo de enfoque mixto, en tanto se recurrió a métodos estadísticos y no estadísticos. El primero, se utilizó para la presentación de 
tablas y figuras, así como para la contratación de las hipótesis planteadas. Se aplicó el método lógico inductivo; el cual permite el razonamiento que, partiendo de casos particulares, se eleva a conocimientos generales. Este método permite la formación de hipótesis, investigación de leyes científicas, y las demostraciones.

El estudio corresponde al diseño no experimental (ex post facto, en tanto no habrá manipulación de variables sino que los datos serán recogidos después de ocurrido el hecho). Asimismo, corresponde a un diseño Descriptivo - Explicativo, es descriptiva, porque mide y describe las variables objeto de estudio, y es explicativa, porque buscar una explicación del por qué de los hechos, mediante el establecimiento de la relación causa-efecto.

Desde el punto de vista geográfico el presente trabajo de investigación es departamental, dado que el estudio comprende los casos de prisión preventiva en el Distrito Fiscal de Tacna durante los años 2013-2014.

Las unidades de estudio lo comprenden los casos en los que se ha solicitado prisión preventiva en el Distrito Fiscal de Tacna durante los años 2013-2014, y los profesionales del derecho en materia penal del Distrito Fiscal de Tacna.

La población de estudio está comprendida por los casos (Carpetas Fiscales) en los que se solicitó prisión preventiva en el Distrito Fiscal de Tacna durante los años 2013-2014. Asimismo, la población de estudio estará comprendida por los profesionales del derecho en materia penal del Distrito Fiscal de Tacna. Definida la población se determinó la muestra de los casos (Carpetas Fiscales) en los que se solicitó de prisión preventiva. Se tomaron en consideración las carpetas fiscales en las cuales se ha solicitado prisión preventiva, además, profesionales del derecho en materia penal (Jueces, Fiscales y abogados). Se excluyen a todos los que no están inmersos en el criterio anterior.

Para la recolección de datos se recurrió a la aplicación del instrumento de medición de la Ficha de Análisis documental, el Cuestionario y la Cédula de entrevista. Las técnicas utilizadas para medir las variables de estudio fueron: el análisis documental, la encuesta, la observación y la entrevista. Para el análisis de las variables de estudio se utilizaron instrumentos de recolección de datos: Ficha de Análisis documental, el Cuestionario y la Cédula de entrevista. La información se procesó electrónicamente, utilizando para ello el programa Microsoft Excel, para presentar los Ítems mediante gráficas $y$, al mismo tiempo estimar las frecuencias absolutas y relativas de cada reactivo para describir la variable de estudio. Se dio a conocer los datos en forma resumida, objetiva y entendible, en el presente trabajo se utilizó el método tabular: tablas, cuadros estadísticos y los gráficos que se utilizaron con fines comparativos para presentar cifras absolutas y/o porcentajes. Se analizó e interpretó la información procesada a través del análisis cuantitativo, cualitativo, y la síntesis.

\section{RESULTADOS}

\section{Análisis de los resultados del cuestionario}

Para conocer la opinión existente, acerca de la incidencia de la inaplicación del principio de Plazo Razonable en la ineficiencia de la etapa de Investigación Preparatoria en los casos de prisión preventiva en el Distrito Fiscal de Tacna durante los años 2013-2014, se ha aplicado una encuesta a los abogados con conocimiento en derecho penal y se aplicó una entrevista a la totalidad de magistrados (100\%) entre Jueces de investigación preparatoria así como Fiscales Provinciales Penales y Adjuntos al Provincial de la especialidad que se desenvuelven en éste Distrito Fiscal. Los resultados relevantes del cuestionario aplicado con la técnica de la encuesta son analizados e interpretados a continuación en tablas y figuras. 
Tabla 01

En los casos de prisión preventiva en la etapa de Investigación Preparatoria se atienden de acuerdo a las necesidades concretas de la investigación.

\begin{tabular}{|l|c|c|}
\hline Alternativas & F & \% \\
\hline a) Si & 33 & 19 \\
\hline b) No & 145 & 81 \\
\hline Total & $\mathbf{1 7 8}$ & 100 \\
\hline
\end{tabular}

Fuente: Cuestionario Aplicado a los abogados

Elaboración: Propia

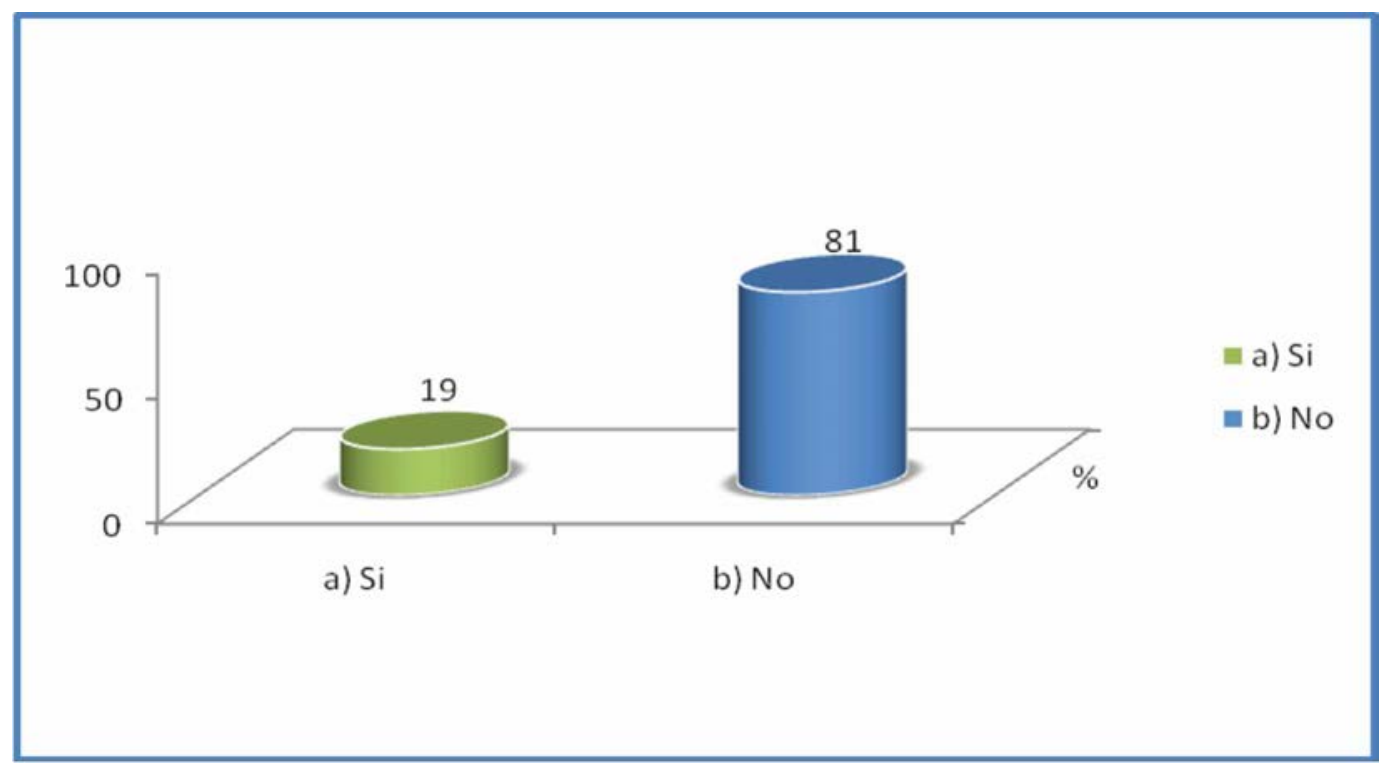

Figura 01

Fuente: Tabla $\mathrm{N}^{\circ} 01$

Elaboración: Propia

\section{INTERPRETACIÓN:}

En la tabla y figura 1, se observa que el $81 \%$ de los encuestados señalan que en los casos de prisión preventiva en la etapa de investigación preparatoria "no" se atienden a las necesidades concretas de la investigación; y el 19\% manifiesta lo contrario.

\section{Tabla 2}

En el Distrito Fiscal de Tacna existen índices considerables de plazos excesivos por la cultura burocrática, de gestión o de mero trámite de los Representantes del Ministerio Público.

\begin{tabular}{|l|c|c|}
\hline Alternativas & $\mathbf{f}$ & $\mathbf{\%}$ \\
\hline a) $\mathrm{Si}$ & 153 & $\mathbf{8 6}$ \\
\hline b) No & 25 & 14 \\
\hline Total & $\mathbf{1 7 8}$ & $\mathbf{1 0 0}$ \\
\hline
\end{tabular}

Fuente: Cuestionario Aplicado a los abogados

Elaboración: Propia 


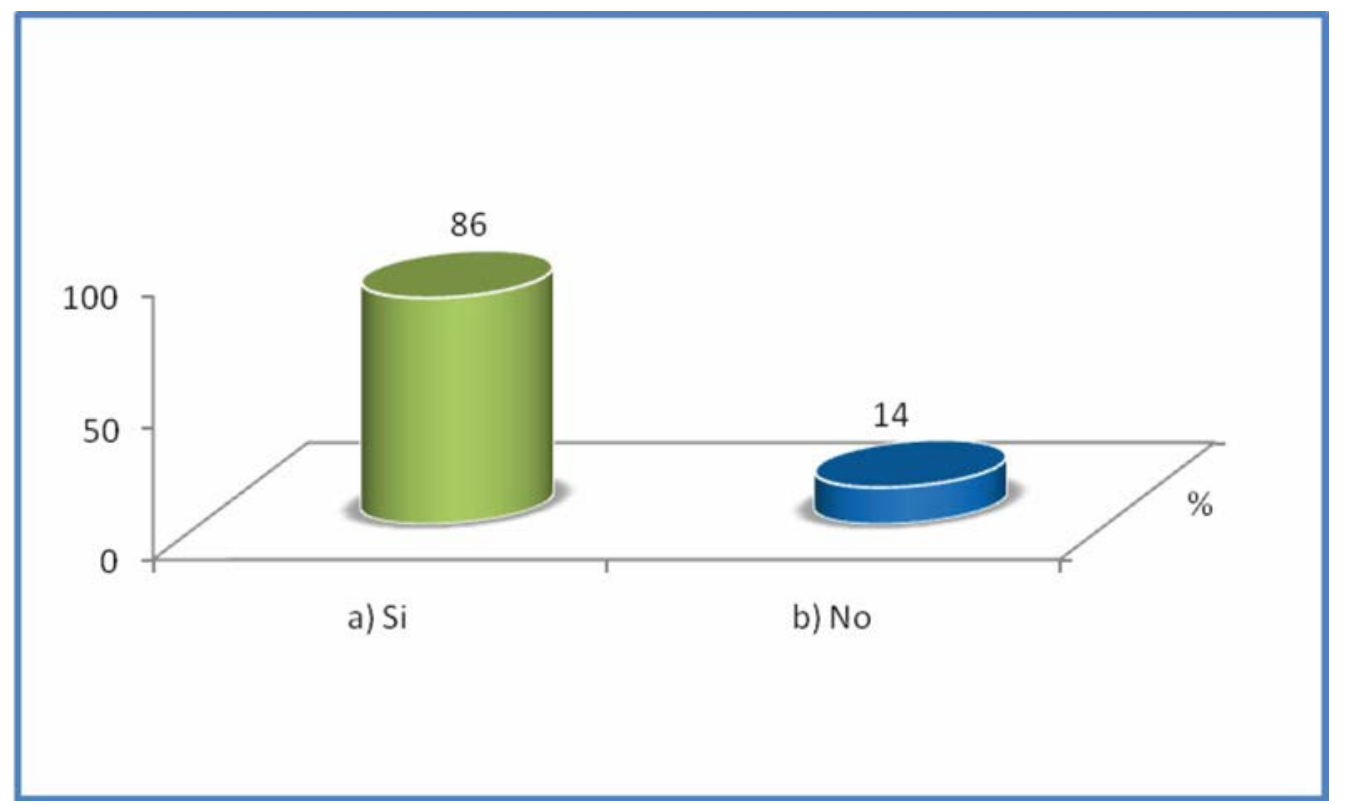

Figura 2

Fuente: Tabla № 02

Elaboración: Propia

\section{INTERPRETACIÓN:}

En la tabla y figura 2, se observa que el $86 \%$ de los encuestados manifiestan que en el Distrito Fiscal de Tacna existen índices considerables de plazos excesivos por la cultura burocrática, de gestión o de mero trámite de los Representantes del Ministerio Público; y el $14 \%$ señala lo contrario.

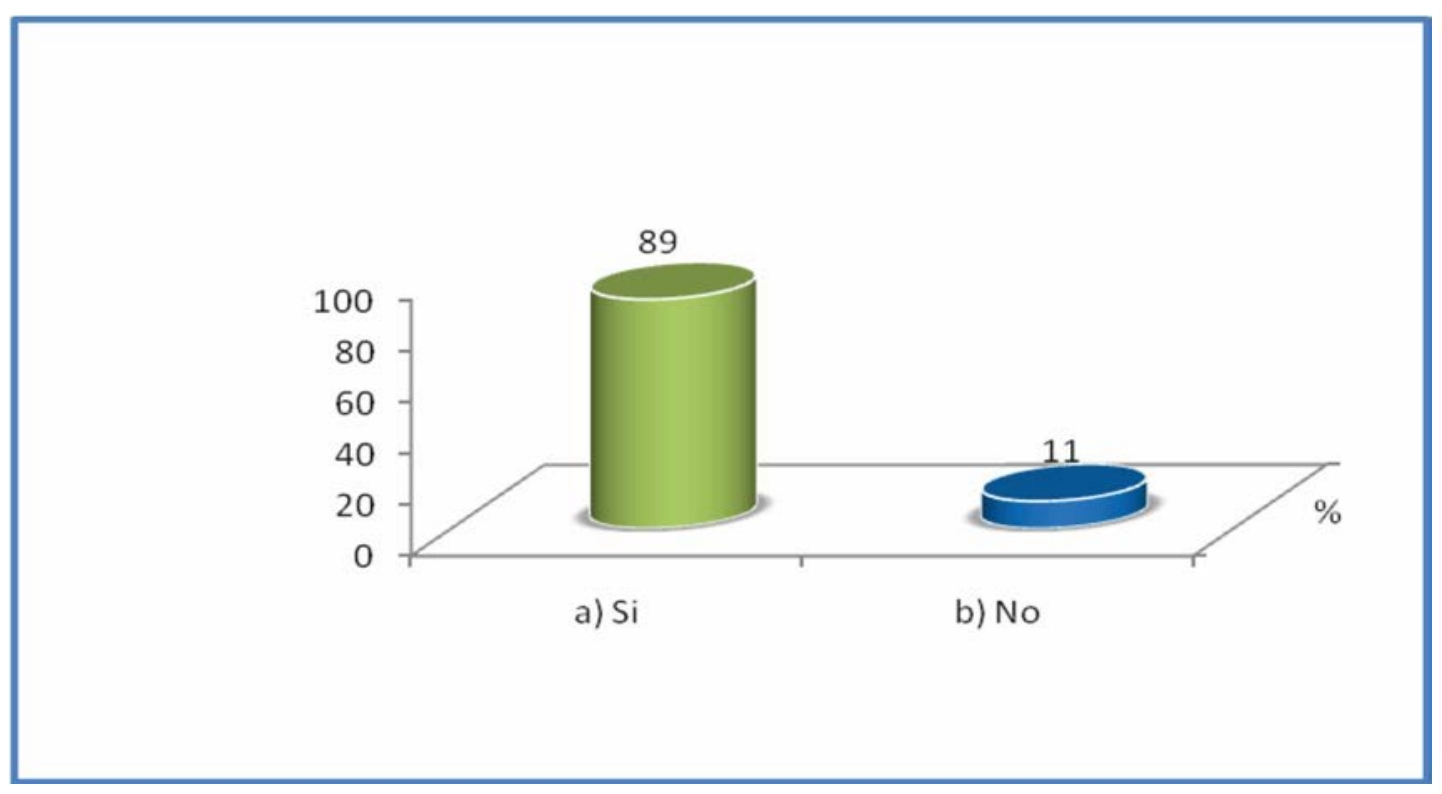

Figura 3: En la etapa de Investigación Preparatoria en los casos de prisión preventiva, se hace uso excesivo de tiempo y recursos para su atención.

Fuente: Elaboración: Propia 


\section{INTERPRETACIÓN:}

En la figura 3, se observa que el $89 \%$ de los encuestados señalan que: en la etapa de investigación preparatoria en los casos de prisión preventiva, se hace uso excesivo de tiempo y recursos para su atención; y, el $11 \%$ señala lo contrario.

\section{Tabla 4}

La inaplicación del principio del Plazo Razonable en los casos de prisión preventiva incide en la ineficiencia de la etapa de Investigación Preparatoria.

\begin{tabular}{|l|c|c|}
\hline Alternativas & F & \% \\
\hline a) $\mathrm{Si}$ & 164 & 92 \\
\hline b) No & 14 & 8 \\
\hline Total & $\mathbf{1 7 8}$ & 100 \\
\hline
\end{tabular}

Fuente: Cuestionario Aplicado a los abogados

Elaboración: Propia

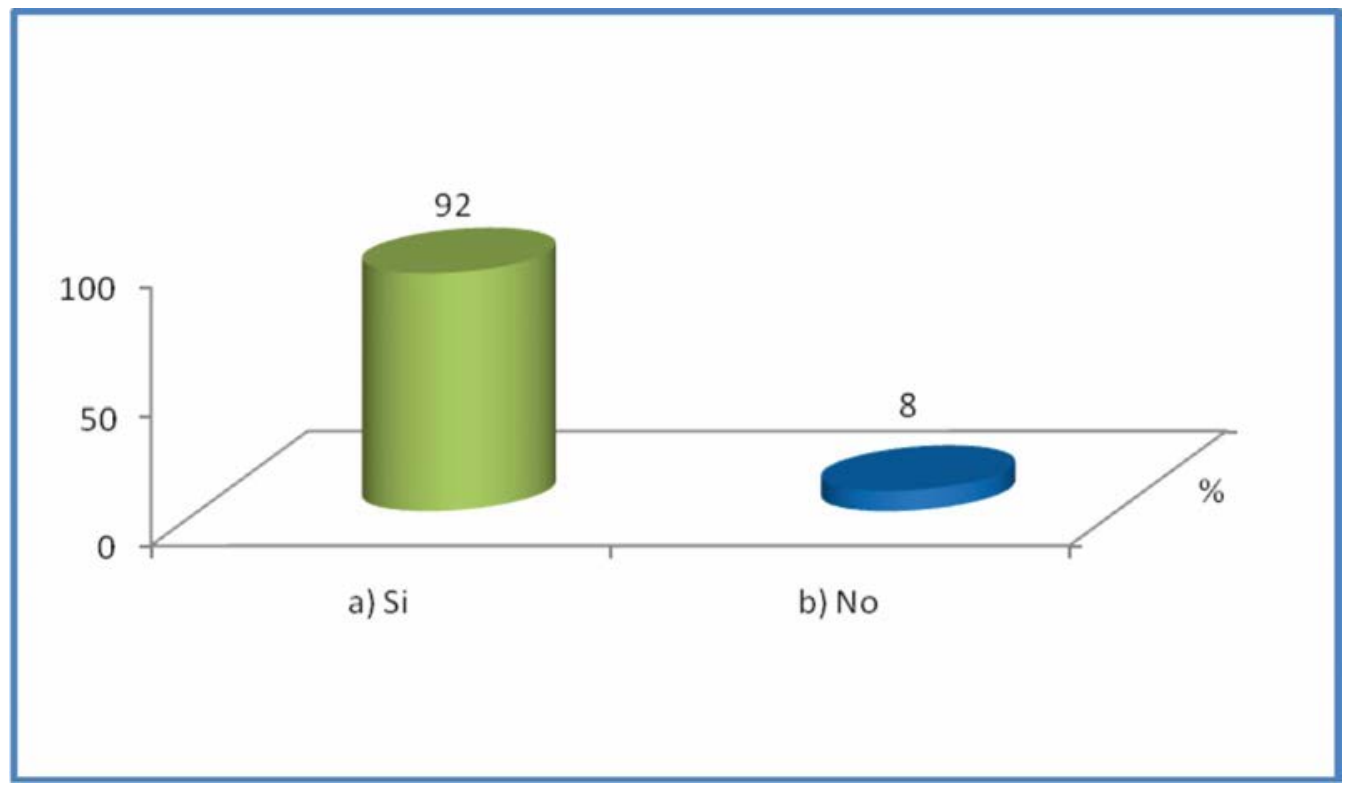

\section{Figura 4}

Fuente: Tabla $\mathrm{N}^{\circ} 10$

Elaboración: Propia

\section{INTERPRETACIÓN:}

En la tabla y figura 4, se observa que el $92 \%$ de los encuestados señalan que: la inaplicación del principio del Plazo Razonable en los casos de prisión preventiva inciden en la ineficiencia de la etapa de investigación preparatoria; $y$, sólo el $8 \%$ señala lo contrario.

\section{Resultados de entrevistas a magistrados.}

A continuación se presenta los resultados de la entrevista aplicada a los magistrados, sobre la problemática de la aplicación del Plazo Razonable en la etapa de investigación preparatoria en los casos de prisión preventiva, no se individualiza o personifica al magistrado a efectos de evitar problemas, por lo que, las presentes entrevistas son anónimas: 
1. ¿Considera usted que en los casos de prisión preventiva en la etapa de investigación preparatoria se atiende las necesidades concretas de la investigación. Fundamente? No, generalmente en los casos de prisión preventiva se utiliza el máximo del plazo legal, sin atender a las necesidades concretas de la investigación, máxime que en estos casos el Representante del Ministerio Público ya ha recabado fundados y graves elementos de convicción.

2. ¿Considera usted que los órganos jurisdiccionales establecen la razonabilidad en concreto del plazo en función de las necesidades reales de la investigación en los casos de prisión preventiva. Fundamente?

Considero que no, ya que no se tiene en cuenta las necesidades reales y concretas de la investigación, en la práctica en estos casos ya se cuenta con la mayoría de elementos de convicción y en vez de establecerse un Plazo Razonable se utiliza el máximo del plazo legal para la investigación preparatoria, incluso, en algunos casos hasta se solicita la prórroga de la investigación preparatoria.

3. ¿Considera usted que la mayoría de Investigaciones Preparatorias de casos de prisión preventiva se atienden en plazos excesivos. Fundamente?

Considero que sí, porque no se toma en cuenta el plazo razonable sino que sencillamente se dispone la formalización de investigación preparatoria por el máximo del plazo legal, y muchas veces sin realizar mayores actos de investigación esperan que dicho plazo concluya para dar por concluida la etapa de investigación preparatoria.

4. ¿Considera usted que la inaplicación del principio del Plazo Razonable en los casos de prisión preventiva inciden en la ineficiencia de la investigación preparatoria. Fundamente?

Sí, pues una investigación preparatoria con plazos excesivos la convierte en una investigación ineficiente, ya que en la práctica solo se deja pasar el plazo de la investigación sin que se hayan realizado los suficientes actos de investigación.

\section{CONCLUSIONES}

En la etapa de Investigación Preparatoria en los casos de prisión preventiva, se aplica el máximo plazo legal, sin tener en consideración que existen mínimos actos de investigación a realizarse durante la etapa de Investigación Preparatoria. Ello se evidencia, ya que no se tiene en cuenta las necesidades reales y concretas de la investigación, en la práctica en estos casos se cuenta con la mayoría de elementos de convicción, dejando de lado el derecho al Plazo Razonable por la utilización del máximo plazo legal.

En la etapa de Investigación Preparatoria en los casos de prisión preventiva, la mayor parte de los procesos son resueltos con plazos excesivos, desatendiéndose las necesidades concretas de la investigación, incidiendo en la morosidad de la etapa de Investigación Preparatoria. Asimismo el excesivo uso de recursos, es otro indicador fundamental para determinar su ineficiencia.

La atención de la mayoría de casos en los que se solicitó la medida restrictiva de prisión preventiva, se tiene una ineficiente investigación en la etapa de Investigación Preparatoria, ya que generan el uso excesivo de recursos y la morosidad en la atención de los casos, siendo lo correcto, establecer el plazo de investigación de acuerdo a cada caso en concreto. 


\section{REFERENCIAS BIBLIOGRÁFICAS}

Aguado Correa, T. (2013). El principio de proporcionalidad en el Derecho Penal Peruano. En E. VILLEGAS PAIVA, La detención y Prisión Preventiva en el nuevo Código Procesal Penal (pág. 115). Lima: GACETA PENAL.

Barallat López, J. (2004). Función Cautelar y función preventiva de la prisión provisional. Madrid: Sepin.

Barnes, J. (2013). El principio de proporcionalidad .Estudio preliminar. En E. VILLEGAS PAIVA, La detención y la Prisión preventiva en el nuevo código Procesal Penal (pág. 117). Lima: El Buho.

Bernal Pulido, C. (2013). El Principio de Proporcionalidad de la legislación Penal. En E. VILLEGAS PAIVA, La detención y la prisión preventiva en el nuevo Código Procesal Penal (pág. 118). Lima: El Buho.

Binder M., A. (2000). Introducción al Derecho Procesal Penal. México: Ad Hoc S.R.L.

Borowski, M. (2003). La estructura de los derechos fundamentales. Bogotá: Universidad Externado de Colombia.

Burgos, V. (2013). La prisión preventiva en el Nuevo Código Procesal Penal de 2004. En E. VILLEGAS PAIVA, La Detención y la Prisión Preventiva en el Nuevo Código Procesal Penal (pág. 104). Lima: El Búho.

Cafferata Nores, J. (2000). La prueba en el proceso penal. Buenos Aires: De Palma.

Castillo Corodova, L. (2013). Criterios de interpretación para evaluar la constitucionalidad del mandato de detención. En E. VILLEGAS PAIVA, La detención y la prisión preventiva en el nuevo Código Procesal penal (pág. 131). Lima: El Buho.

De la Matta Barranco, N. (2013). Aspectos nucleares del concepto de proporcionalidad de la intervención penal. En E. VILLEGAS PAIVA, La Detención y la Prisión Preventiva en el Nuevo Código Procesal Penal (pág. 112). Lima: GACETA PENAL.

Del Rio Labarthe, G. (2013). La prisión preventiva en la Jurisprudencia del Tribunal Constitucional. En E. Villegas Paiva, La Detención y la prisión preventiva en el Nuevo Código Procesal Penal (pág. 222). Lima: El Búho.

Faraldo Cabana, P. (2013). El proyecto de reforma de la Ley de Enjuiciamiento criminal en materia de prisión provisional. En E. VILLEGAS PAIVA, La Detención y la Prisión Preventiva en el Nuevo Código Procesal Penal (pág. 100). Lima: El Búho.

Ferrajoli, L. (2008). Derecho y Razón. Teoría del Garantismo Penal. Madrid: Trotta.

Ferrer Beltran, J. (2013). Una Concepción Minimalista y garantista de la presunción de inocencia. En E. VILLEGAS PAIVA, La Detención y la Prisión Preventiva en el Nuevo Código Procesal Penal (pág. 87). Lima: El Búho.

Huerta Tocildo, S. (2013). El derecho fundamental a la legalidad en el Nuevo Código Procesal Penal de 2004. En E. VILLEGAS PAIVA, La Detención y la Prisión Preventiva en el Nuevo Código Procesal Penal (pág. 104). Lima: El Búho.

López Viñal, P. y. (2013). Garantías del Imputado. En E. VILLEGAS PAIVA, La Detención y la Prisión Preventiva en el Nuevo Código Procesal Penal (pág. 108). Lima: El Búho.

Miranda Estrampes, M. (2013). La Valoración de la prueba a la luz del Nuevo Código Procesal Penal Peruano. En E. VILLEGAS PAIVA, La Detención y la Prisión Preventiva en el Nuevo Código Procesal Penal (pág. 90). Lima: El Búho.

Mixám Mass, F. (2003). Derecho Procesal Penal. Trujillo: BGL.

Moreno Catena, V. (2000). Las medidas cautelares en el proceso penal. La detención. Valencia: Tirant Lo Blanch.

Neyra Flores, J. A. (2010). Manual del Nuevo Proceso Penal \& de Litigación Oral. Lima: IDEMSA.

Noguera Alaclá, H. (2013). Consideraciones sobre el Derecho fundamental a la presunción de inocencia. En E. VILLEGAS PAIVA, La Detención y la Prisión Preventiva en el Nuevo Código Procesal Penal (pág. 87). Lima: El Búho.

Oré Gurdia, A. (2013). Las medidas cautelares personales en el proceso penal peruano. En E. VILLEGAS PAIVA, La Detención y la Prisión Preventiva en el Nuevo Código Procesal Penal (pág. 115). Lima: El Búho. 
Pastor, D. (2013). El plazo razonable en el proceso del Estado de Derecho. En E. VILLEGAS PAIVA, La Detención y la Prisión Preventiva en el Nuevo Código Procesal Penal (pág. 84). Lima: El Búho.

Peña Cabrera, A. (2013). La libertar por exceso de detención. El derecho de ser juzgado en un plazo razonable. En E. VILLEGAS PAIVA, La Detención y la Prisión Preventiva en el Nuevo Código Procesal Penal (pág. 109). Lima: Rhodas.

Reategui Sanchez, J. (2013). En busca de la prisión preventiva. En E. VILLEGAS PAIVA, La detención y la prisión preventiva en el nuevo Código Procesal Penal (pág. 149). Lima: El Buho.

Reyes Alvarado, V. R. (2007). Las medidas de coerción procesal personal en el NCPP del 2004. Gaceta Jurídica, 183.

Reyna Alfaro, L. M. (2013). El Proceso Penal aplicado conforme al Código Procesal Penal del 2004.2. En E. VILLEGAS PAIVA, La Detención y la Prisión Preventiva en el Nuevo Código Procesal Penal (pág. 88). Lima: El Búho.

Sanguiné, O. (2013). La prisión provisional y derechos fundamentales. En E. VILLEGAS PAIVA, La Detención y la Prisión Preventiva en el Nuevo Código Procesal Penal (pág. 114). Lima: El Búho.

Suarez López de Castilla, C. (2013). ¿De qué hablamos cuando hablamos de legalidad procesal penal? En E. VILLEGAS PAIVA, La Detención y la Prisión Preventiva (pág. 107). Lima: GACETA PENAL.

Vasquez, M. (2006). DETENCIÓN Y LIBERTAD EN EL PROCESO PENAL. Actualidad Jurídica, Gaceta Jurídica.

Vega Torres, J. (2013). La presunción de inocencia del artículo 24.2 de la Constitución en el proceso penal español. En E. VILLEGAS PAIVA, La Detención y la Prisión Preventiva en el Nuevo Código Procesal Penal (pág. 99). Lima: GACETA PENAL.

Recibido: 14/10/2016

Aceptado para publicarse:

$4 / 11 / 2016$ 